\title{
ASSESSMENT OF PSYCHIATRIC PATIENTS' PERCEPTIONS, VIEWS, AND SATISFACTIONS WITH THE ROLES OF PHARMACISTS IN MENTAL HEALTH CARE - A STUDY IN A NIGERIA PSYCHIATRIC HOSPITAL
}

\author{
OFOR AMALA C* \\ Department of Clinical Pharmacy and Biopharmaceutics, Faculty of Pharmaceutical Sciences, Enugu State University of Science and \\ Technology, Agbani, Enugu, Nigeria. Email: amala.ofor@esut.edu.ng
}

Received: 15 April 2020, Revised and Accepted: 10 May 2021

\section{ABSTRACT}

Objectives: To assess the psychiatric patients' perception, views, and satisfactions with the pharmacists' role in mental health care.

Methods: The study was conducted in a Neuropsychiatric Hospital in South Eastern part of Nigeria from October 2019 through January 2020 using a cross sectional survey in convenient samples and a total of 128 patients completed the study. The questionnaire contained the patients' demographic details, six-item questions on respondents' perception, 7-item questions on patients' satisfaction, and six-item questions on the respondents' view. The questionnaire was coded, checked for accuracy and analyzed using statistical package for social sciences version 23 for windows.

Results: The response rate was $94 \%$ where 136 respondents showed willingness to participate, but 128 respondents completed the study. All the participants were young adults and adults, male (53.1\%), female (46.9\%). About $93.8 \%$ of the respondents agreed that the pharmacists were friendly and $89.1 \%$ admitted that pharmacists' care were about perfect. About $69.5 \%$ were satisfied with the pharmacists' professional outlook, while only $42.2 \%$ are of the view that the pharmacists offer counseling without their asking for it.

Conclusion: The patients' perception on the pharmacists' skills and knowledge in handling psychiatric patients was high; their satisfaction with the pharmacists' professional outlook can be considered fair, while their views on pharmacists' counseling can be considered to be generally poor.

Keywords: Psychiatric patients, Perceptions, Views, and Satisfactions, Pharmacists, Mental health, care, Nigeria.

(C) 2021 The Authors. Published by Innovare Academic Sciences Pvt Ltd. This is an open access article under the CC BY license (http://creativecommons.org/ licenses/by/4.0/) DOI: http://dx.doi.org/10.22159/ajpcr.2021v14i8.37922. Journal homepage: https://innovareacademics.in/journals/index.php/ajpcr

\section{INTRODUCTION}

Mental illness is often seen as a public health burden and of great concern to the caregivers, health workers, friends, and family members. In severe conditions, the patients become a societal problem and as well unable to perform meaningful tasks and contributions to the society. As much as 450 million people worldwide may be termed mentally disordered [1]; while Nigeria account up to 40 million sufferers [2] with $85 \%$ of youths in that number probably due to their involvement with substance abuse [3]. Moreover, Nigeria is part of conflict-induced countries where it is slated that mental illness is highest in, with stigmatization the greatest problems that faces the patients in those areas, which leads to leaving a reasonable proportion of the patients to cope with themselves with few of them receiving the most basic treatment [4]. However, there should be increasing need for the pharmacists in Nigeria to be adequately equipped with necessary knowledge and skills in the management of psychiatric illness. The perceptions and satisfactions of the patients and/or caregivers on the pharmacists' knowledge and skills in mental care can be important measures on their treatment outcomes. Thus, the purpose of this study was to evaluate the psychiatric patients' perceptions, views, and satisfactions on the pharmacists' role in mental care. The study specifically assessed the patients' perceptions on the pharmacists' knowledge and skills, the patients' views on the pharmacists' counseling abilities, and the patients' satisfactions on the pharmacists' professional outlook; in mental health care.

\section{METHODS}

Study site

The study was conducted in Anambra State Neuropsychiatric Hospital, Nawfia, Anambra State, Southeast, and Nigeria from October 2019 through January 2020. The hospital is located at about $4 \mathrm{~km}$ from the State Capital, and about $35 \mathrm{~km}$ from the State Commercial City Centre. It is the state's only neuropsychiatric hospital with an average of 70 daily clientele with most of the patients schizophrenic, autistic disordered, mood disordered, and drug addicts; and basically serves as a referral center for neuropsychiatric cases. It comprises a general outpatient department, two pharmacy dispensary units, one medical laboratory, two male wards each for acute and recovery cases), two female wards (each for acute and recovery states), a staff general office, a waiting room, and a nursing students' hostel. As at the time the study was conducted, there were three physicians (one psychiatric and two general practitioners), three pharmacists, two psychologists and 15 nurses. The hospital management ensured that all the prescription drugs for psychiatric treatments in the hospital must be obtained by the patients from the hospital's pharmacy department.

\section{Study population description}

The study was carried out among mild to moderate mentally disordered adult patients that visited Anambra State Neuropsychiatric Hospital, Nawfia for treatment, counseling, or trying to fill prescriptions.

\section{Study design}

A cross sectional study using questionnaire to collect information regarding the perceptions, views, and satisfaction of the psychiatric patients towards pharmacists' competence in mental illness management.

\section{Inclusion criteria}

The following criteria were included in the study:

1. Patient must be from 18 years of age

2. Must be taking at least one medication dispensed at the hospital pharmacy for treatment of a diagnosed mental illness. 


\section{Exclusion criteria}

The following criteria were excluded from the study:

1. Those considered inappropriate for the survey regarding illness severity, issues of illiteracy and competence

2. Inability to provide a caregiver/family member when not in a position to complete the questionnaire.

\section{Study instrument}

The questionnaire used contained two sections: Sections A and B. Section A contained the respondents' demographic details, while Section B contained (i) six-items questions on respondents' perception, adopted from Bawazir study [5], (ii) seven-items questions on respondents' satisfaction, adopted from Gidman et al. study [6], (iii) six-items questions on respondents' view adopted from Hajj et al. [7] (Table 1). The format of the questionnaire was nominal (three-likert scale). Each of the questions contained: Agree, undecided, and disagree options.

\section{Data collection}

All the patients or their caregivers or family members that visited the hospital were informed and invited to participate in the study. The purpose of the study was explained and those that were interested in participating were given the survey questionnaire along with brief instructions on how to complete it. A pilot test was conducted in 12 patients using the developed questionnaire in other to achieve validation of the questionnaire. From the result of the pilot test, a little modification was made for the suitability of the questionnaire. The final version of the questionnaire was used for the study. Identification of the patients that met inclusion criteria was done by a psychologist working in the hospital, while the researcher was given a separate unit far from the dispensary for the data collection.

\section{Table 1: Complete list of items used in the survey}

\begin{tabular}{|c|c|}
\hline Q. No. & Respondents Perception \\
\hline 1 & $\begin{array}{l}\text { I have been receiving about a perfect care from the } \\
\text { pharmacists }\end{array}$ \\
\hline 2 & $\begin{array}{l}\text { Sometimes I doubt if the pharmacists are dispensing the } \\
\text { prescribed drugs }\end{array}$ \\
\hline 3 & $\begin{array}{l}\text { Pharmacists are too business-like and do not care about my } \\
\text { medication needs }\end{array}$ \\
\hline 4 & Pharmacists treat me in a very friendly manner \\
\hline 5 & Pharmacists sometimes ignore what I tell them \\
\hline 6 & Pharmacists do not have ability to handle my medications \\
\hline \multicolumn{2}{|c|}{ Respondents view } \\
\hline 1 & $\begin{array}{l}\text { Pharmacists are mere vendors/dispensers of prescription } \\
\text { drugs }\end{array}$ \\
\hline 2 & Pharmacists usually offer counseling without my asking for it \\
\hline 3 & $\begin{array}{l}\text { Pharmacists try to extract information about the } \\
\text { compliance to the previously dispensed medications }\end{array}$ \\
\hline 4 & $\begin{array}{l}\text { Pharmacists enquire about my health related problems and } \\
\text { any other medications I used in the past }\end{array}$ \\
\hline 5 & $\begin{array}{l}\text { Pharmacists are indispensable professionals and effective } \\
\text { part of health care system }\end{array}$ \\
\hline 6 & $\begin{array}{l}\text { Pharmacists do not instruct about the timing of drug } \\
\text { administration }\end{array}$ \\
\hline \multicolumn{2}{|c|}{ Respondents satisfaction } \\
\hline 1 & Pharmacists give me the courtesy and respect I need \\
\hline 2 & $\begin{array}{l}\text { Pharmacists are available at the designated hour to answer } \\
\text { the questions I need }\end{array}$ \\
\hline 3 & It takes a long time to get prescription filled at the pharmacy \\
\hline 4 & $\begin{array}{l}\text { Pharmacists frequently ask me how well my medications } \\
\text { are working }\end{array}$ \\
\hline 5 & $\begin{array}{l}\text { Pharmacists give me help to avoid unnecessary cost related } \\
\text { to prescriptions }\end{array}$ \\
\hline 6 & Pharmacists give a professional appearance \\
\hline 7 & $\begin{array}{l}\text { I am pleased with the pharmacists help when a drug does } \\
\text { not have the expected effect }\end{array}$ \\
\hline
\end{tabular}

\section{Data analysis}

Each questionnaire was coded, checked for accuracy and analyzed using statistical Package Social Science version 23.0 for Windows. The analysis included code transcriptors, cross-tabulation of the variables and frequencies of discrete variables. Assessment of statistical significance considering the patients' response, sex, and age group responses in their perception, views and satisfactions. Chisquare test was used, assuming that there is a significant difference if $\mathrm{p}<0.05$

\section{Ethical issues}

The patients were made aware that participation was voluntary and they had the right to refuse or discontinue, and the investigator can terminate a subject's participation if the subject met an exclusion criterion, either by deliberately providing false information or not following the study procedure. An assurance was given to the patients that their identity was not needed.

A study code for the purpose of data was used to ensure confidentiality of information. Ethical clearance was obtained from Chukwuemeka Odumegwu Ojukwu Teaching Hospital, Awka Ethics Committee (Ref: COOUTH/CMAC/ETH.C/VOL.1/0107). Permission from the hospital management was requested and obtained to approach outpatient patients when they were waiting for their appointment.

\section{RESULTS}

Out of 136 patients that showed willingness to participate in the study, 128 patients completed the study while 8 patients defaulted. The subjects' reasons for the default were: Insufficient time since it was getting to their turn to see the doctor (five patients), the questionnaire were too cumbersome to fill (three patients).

\section{Demographic data of the respondents}

The demographic features of the respondents included - gender, age religion and ethnicity (Table 2). It showed that of the 128 respondents who successfully completed the questionnaire, $68(53.1 \%)$ were males while $60(46.9 \%)$ were females. Majority of the respondents that participated were aged 40 years and above. Virtually all respondents were Christians (96.9\%) and of Igbo origin (97.7\%) (Table 2).

\section{Patients' response}

Knowledge and skills

The pharmacist is a professional that is well trained with adequate skills in attending to the patients, as well as handling medications that concerns the patients. The results showed that a large number of respondents identified the pharmacists' ability in handling psychiatric patients. As much as $93.8 \%$ of the respondents agreed that they were treated in a friendly manner by the pharmacists; $89.1 \%$ of the respondents also agreed that the care they receive from the pharmacists were about perfect. While very few (2.3\%) of the respondents showed

Table 2: Demographic data of respondents

\begin{tabular}{ll}
\hline Respondents & Frequency (\%) \\
\hline Gender & \\
Male & $68(53.1)$ \\
Female & $60(46.9)$ \\
Age & \\
$20-29$ & $18(14.1)$ \\
$30-39$ & $48(37.5)$ \\
40 and above & $62(48.4)$ \\
Religion & \\
Christian & $124(96.9)$ \\
Tradition & $4(3.1)$ \\
Ethnicity & \\
Igbo & $125(97.7)$ \\
Others & $3(2.3)$ \\
\hline
\end{tabular}


that the pharmacists are too business-like without caring about their medication needs (Table 3), and $64.8 \%$ of the respondents agreed that the pharmacists try to extract information about the previously dispensed medication (Tables 4 and 5). However, with respect to gender, the $83.3 \%$ of the respondents that disagreed that the pharmacists treat them in a friendly manner (Table 6), and as well as the $74.1 \%$ that disagreed that the pharmacists try to extract information about the compliance of previously dispensed medication (Tables 7 and 8), were males. Moreover, $76.0 \%$ of those that disagreed that the pharmacists enquire about their health related problems and any other medications used in the past were females (Table 8). When considering age, 66.6\% of the respondents between the ages of 20 and 29 years disagreed that the pharmacists treat them in a friendly manner (Table 9); but for ages from 40 years, $61.5 \%$ agreed that the pharmacists try to extract information about the compliance of the previously dispensed medication (Tables 10 and 11)

\section{Professional appearance}

The professional outlook of the pharmacists inspires trust in the patients [8]. The results show that $69.5 \%$ of the respondents were satisfied with the pharmacists' professional appearance (Table 4), while among the male versus female groups, the majority $(85.7 \%)$ of the respondents that could not make decisions, were males. When considering the age groups, $60.7 \%$ of the respondents that agreed that the pharmacists give professional appearance were from 40 years (Table 10).

Table 3: Patients' response to perception

\begin{tabular}{lll}
\hline Agree (A) n (\%) & Undecided (U) n (\%) & Disagree (D) n (\%) \\
\hline $114(89.1)$ & $9(7)$ & $5(3.9)$ \\
$93(72.7)$ & $25(19.5)$ & $10(7.8)$ \\
$3(2.3)$ & $11(8.6)$ & $114(89.1)$ \\
$120(93.8)$ & $3(2.3)$ & $5(3.9)$ \\
$22(17.2)$ & $14(10.9)$ & $92(71.9)$ \\
$28(21.9)$ & $22(17.2)$ & $78(60.9)$ \\
\hline
\end{tabular}

Table 4: Patients' response on satisfaction

\begin{tabular}{lll}
\hline Agree (A) n (\%) & Undecided (U) n (\%) & Disagree (D) n (\%) \\
\hline $108(84.4)$ & $14(10.9)$ & $6(4.7)$ \\
$90(70.3)$ & $28(21.9)$ & $10(7.8)$ \\
$14(10.9)$ & $11(8.6)$ & $103(80.5)$ \\
$73(57.0)$ & $18(14.1)$ & $37(28.9)$ \\
$71(55.5)$ & $40(31.2)$ & $17(13.3)$ \\
$89(69.5)$ & $14(11.0)$ & $25(19.5)$ \\
$82(64.0)$ & $37(29.0)$ & $9(7.0)$ \\
\hline
\end{tabular}

Table 5: Patients' response to view

\begin{tabular}{lll}
\hline Agree (A) n (\%) & Undecided (U) n (\%) & Disagree (D) n (\%) \\
\hline $80(62.5)$ & $25(19.5)$ & $23(18.0)$ \\
$54(42.2)$ & $26(20.3)$ & $48(37.5)$ \\
$83(64.8)$ & $8(6.3)$ & $37(28.9)$ \\
$69(53.9)$ & $34(26.6)$ & $25(19.5)$ \\
$121(94.5)$ & $6(4.7)$ & $1(0.8)$ \\
$12(9.4)$ & $9(7.0)$ & $107(83.6)$ \\
\hline
\end{tabular}

Counseling

The results show that $42.2 \%$ of the respondents were of the view that the pharmacists usually offer counseling without the patients asking for it; and about $37.5 \%$ were of the view that they do not usually offer counseling without the patients asking for it (Table 5). However, among the sex groups there was no statistical significant difference $(p=0.882$ ) (Table 8). While considering the age groups, above $40 \%$ of the respondents were in ages between 30 and 39 (48.1\%), and from $40(42.6 \%)$ agreed that pharmacists offer counseling without their asking for it (Table 11), while for the age between 20 and 29 had $9.2 \%$ (Table 11).

\section{DISCUSSION}

The response rate of those approached can be said to be impressive, about $94 \%$. Several factors may be responsible to the high response rate. The factors may include; the use of simple English language (without medical jargons) in the questionnaire, the filling of the questionnaire at the time of convenience before the attention of the doctor, and making the patient feel that the questions were part of their treatment protocol. Although the major role of the pharmacists is dispensing, the role has expanded and the psychiatric patients expect pro-active measures from the pharmacists. They expect the pharmacists to treat them in a friendly manner, enquire about their health-related problems, and as well extract information on the medications they use. Majority of the male patients showed that the pharmacists treat them in a friendly way and the care they receive from the pharmacists were about perfect. However, majority of the females were not of the opinion. This may be related to the gender of the dispensing pharmacists (a saying of "like poles repel"). Furthermore, a close look showed that majority of those above 40 years agreed of the pharmacists' reactiveness in extracting information about their compliance to medication use. This may be as a result of the fact that in this part of the world (Nigeria), attention is mostly given to elderly ones on their health and health-related issues. On the other hand, the patients were satisfied with the pharmacists' ability in mental health care through their attitude and professional outlook, this is in line with the study that identified that patients prefer the pharmacists with white coat regardless of the setting [9]. Moreover, there is greater patients' satisfaction rating when there is higher frequency of counseling $[10,11]$, several barriers can be responsible for the pharmacists not performing this task. This may include the structure of the dispensaries, lack of time considering the number of clientele, poor physician - pharmacist communication in other to identify the drug-therapy problems, inadequate number of qualified pharmacists, and unease of the patients to discuss their condition due to stigma [5]. However, majority of the older patients agreed that the pharmacists offer counseling without the patients seeking for it compared to younger individuals in the age between 20 and 29 years. This is consistent with studies that compared age-related difference between the clinician-patient interaction and patient satisfaction [12].

Although the research was diligently conducted, there were some methodological limitations. First; the subjects used were based on physical assessment of the patients as was reported by the psychologists and the psychiatric doctors working in the hospital that the patients interviewed were in stable psychiatric condition as at the time of approach. Second; since the patients were waiting for appointment, there may be possibility of not concentrating while filling

Table 6: Relationship to Patients' perception in relationship to gender

\begin{tabular}{|c|c|c|c|c|c|c|c|}
\hline \multicolumn{3}{|l|}{ Male } & \multicolumn{3}{|l|}{ Female } & \multirow{2}{*}{$\begin{array}{l}\text { Chi-square value } \\
0.374\end{array}$} & \multirow{2}{*}{$\begin{array}{l}\text { p-value } \\
0.829\end{array}$} \\
\hline $61(53.5)$ & $5(55.5)$ & $2(40.0)$ & $53(46.5)$ & $4(45.5)$ & $3(60.0)$ & & \\
\hline $45(48.4)$ & $16(64.0)$ & $7(70.0)$ & 48 (51.6) & $9(36.0)$ & $3(30.0)$ & 3.169 & 0.205 \\
\hline $2(66.7)$ & $8(72.7)$ & $58(50.0)$ & $1(33.3)$ & $3(27.3)$ & $56(49.1)$ & 2.15 & 0.341 \\
\hline $60(50.4)$ & $3(100.0)$ & $5(83.3)$ & $59(49.6)$ & $0(0.0)$ & $1(16.7)$ & 5.195 & 0.074 \\
\hline $16(72.7)$ & $5(35.7)$ & 47 (51.9) & $6(27.3)$ & $9(64.3)$ & $45(48.1)$ & 5.252 & 0.072 \\
\hline $21(75.0)$ & $15(68.2)$ & $32(41.0)$ & $7(25.0)$ & 7 (31.8) & $46(59.0)$ & 11.969 & ${ }^{*} 0.003$ \\
\hline
\end{tabular}


Table 7: Relationship to patients' response on satisfaction according to gender

\begin{tabular}{|c|c|c|c|c|c|c|c|}
\hline \multicolumn{3}{|l|}{ Male } & \multicolumn{3}{|l|}{ Female } & \multirow{2}{*}{$\begin{array}{l}\text { Chi-square value } \\
7.768\end{array}$} & \multirow{2}{*}{$\frac{\text { p-value }}{0.021 *}$} \\
\hline $63(58.3)$ & $4(28.6)$ & $1(20.0)$ & $45(41.7)$ & $10(71.4)$ & $5(80.0)$ & & \\
\hline $54(60.0)$ & $8(28.6)$ & $6(60.0)$ & $36(40.0)$ & $20(71.4)$ & $4(40.0)$ & 8.677 & $0.013 *$ \\
\hline $8(57.1)$ & $5(45.5)$ & $55(53.4)$ & $6(42.9)$ & $6(54.5)$ & $48(46.6)$ & 0.354 & 0.838 \\
\hline $42(57.5)$ & 7 (38.9) & $19(51.4)$ & $31(42.5)$ & $11(61.1)$ & $18(48.6)$ & 10.231 & $0.006^{*}$ \\
\hline $40(56.3)$ & $22(55.0)$ & $6(35.3)$ & 31 (43.7) & $18(45.0$ & $11(64.7)$ & 2.521 & 0.283 \\
\hline $43(48.3)$ & $12(85.7)$ & $13(52.0)$ & $46(51.7)$ & $2(14.3)$ & $12(48.0)$ & 6.811 & $0.033^{*}$ \\
\hline $46(51.1)$ & $2(20.0)$ & $12(60.0)$ & $44(48.9)$ & $8(80.0)$ & $8(40.0)$ & 4.444 & 0.108 \\
\hline
\end{tabular}

Table 8: Relationship to respondents views according to gender

\begin{tabular}{|c|c|c|c|c|c|c|c|}
\hline Male & & & Female & & & Chi-square value & p-value \\
\hline $26(38.2)$ & $23(92.0)$ & $9(34.1)$ & $42(61.8)$ & $2(8.0)$ & $14(65.9)$ & 22.492 & $<0.001 *$ \\
\hline 30 (55.6) & $13(50.0)$ & $25(52.1)$ & $24(44.4)$ & $13(50.0)$ & 23 (47.9) & 0.251 & 0.882 \\
\hline $35(42.2)$ & $3(37.5)$ & $20(74.1)$ & $48(57.8)$ & $5(62.5)$ & $7(25.9)$ & 8.764 & $0.013^{*}$ \\
\hline $42(60.1)$ & $20(58.8)$ & $6(24.0)$ & 27 (39.9) & $14(41.2)$ & $19(76.0)$ & 10.621 & $0.005^{*}$ \\
\hline 64 (52.9) & $4(66.7)$ & $0(0.0)$ & $57(47.1)$ & $2(33.3)$ & $1(100.0)$ & 3.215 & 0.200 \\
\hline $10(83.3)$ & 7 (77.8) & $51(47.7)$ & $2(16.7)$ & $2(22.2)$ & $56(52.3)$ & 7.876 & $0.019 *$ \\
\hline
\end{tabular}

Table 9: Relationship to patients response to perception according to age

\begin{tabular}{|c|c|c|c|c|c|c|c|c|c|c|}
\hline \multicolumn{3}{|l|}{$20-29$} & \multicolumn{3}{|l|}{ 30-39 } & \multicolumn{3}{|c|}{40 and Above } & \multirow{2}{*}{$\begin{array}{l}\text { Chi-square value } \\
43.895\end{array}$} & \multirow{2}{*}{$\frac{\text { p-value }}{<0.001^{*}}$} \\
\hline $8(7.0)$ & $6(66.7)$ & $4(80.0)$ & $45(39.5)$ & $2(22.2)$ & $1(20.0)$ & $61(53.5)$ & $1(11.1)$ & $0(0.0)$ & & \\
\hline $10(10.8)$ & $3(12.0)$ & $5(62.5)$ & $32(34.4)$ & $13(52.0)$ & $1(12.5)$ & $51(54.8)$ & $9(36.0)$ & $2(25.0)$ & 19.379 & $0.001 *$ \\
\hline $3(100.0)$ & $1(9.1)$ & $14(12.3)$ & $0(0.0)$ & $8(72.7)$ & $40(35.1)$ & $0(0.0)$ & $2(18.2)$ & $60(52.6)$ & 43.723 & $<0.001^{*}$ \\
\hline $13(10.9)$ & $1(33.3)$ & $4(66.6)$ & $45(37.8)$ & $2(66.7)$ & 1 (16.7) & $61(51.2)$ & $0(0.0)$ & $1(16.7)$ & 17.710 & $<0.001 *$ \\
\hline $10(45.5)$ & $3(21.4)$ & $5(5.4)$ & $11(50.0)$ & $10(71.4)$ & $27(29.3)$ & $1(4.5)$ & $1(7.2)$ & $60(65.2)$ & 46.698 & $<0.001^{*}$ \\
\hline $0(0.0)$ & $0(0.0)$ & $0(0.0)$ & $16(76.2)$ & 15 (93.8) & 17 (23.3) & $5(23.8)$ & $1(6.2)$ & $56(76.7)$ & 37.676 & $<0.001 *$ \\
\hline
\end{tabular}

Table 10: Relationship to patients' response to satisfaction according to age

\begin{tabular}{|c|c|c|c|c|c|c|c|c|c|c|}
\hline \multicolumn{3}{|c|}{ 20-29 (years) } & \multicolumn{3}{|c|}{ 30-39 (years) } & \multicolumn{3}{|c|}{40 and Above (years) } & \multirow{2}{*}{$\begin{array}{l}\text { Chi-square value } \\
54.930\end{array}$} & \multirow{2}{*}{$\frac{\text { p-value }}{<0.001^{*}}$} \\
\hline $5(4.5)$ & $10(71.4)$ & $3(50.0)$ & 43 (39.9) & $2(14.3)$ & $3(50.0)$ & $60(55.6)$ & $2(14.3)$ & $0(0.0)$ & & \\
\hline $2(2.2)$ & $13(52.0)$ & $3(30.0)$ & 37 (41.1) & $6(24.0)$ & $5(50.0)$ & $51(56.7)$ & $9(36.0)$ & $2(20.0)$ & 38.758 & $<0.001 *$ \\
\hline $5(35.7)$ & $3(27.3)$ & $10(13.9)$ & $6(42.9)$ & $6(54.5)$ & $5(6.9)$ & $3(21.4)$ & $2(18.2)$ & $57(79.2)$ & 52.736 & $<0.001 *$ \\
\hline $6(8.5)$ & $9(45.0)$ & $3(8.1)$ & $24(33.8)$ & $8(40.0)$ & $16(43.2)$ & $41(57.7)$ & $3(15.0)$ & $18(48.7)$ & 22.640 & $<0.001 *$ \\
\hline 8 (11.3) & $7(17.5)$ & $3(17.6)$ & $14(19.7)$ & $24(60.0)$ & $10(58.8)$ & $49(69.0)$ & $9(22.5)$ & $4(23.6)$ & 30.916 & $<0.001 *$ \\
\hline $8(9.0)$ & $0(0.0)$ & $10(40.0)$ & $27(30.3)$ & $24(85.7)$ & $11(44.0)$ & $54(60.7)$ & $4(14.3)$ & $4(16.0)$ & 31.114 & $<0.001^{*}$ \\
\hline $6(7.3)$ & $9(24.3)$ & $3(33.3)$ & $29(35.4)$ & $15(40.5)$ & $4(44.5)$ & 47 (57.3) & $13(35.1)$ & $2(22.2)$ & 12.071 & $0.017^{*}$ \\
\hline
\end{tabular}

Table 11: Relationship to patients' response to views according to age

\begin{tabular}{|c|c|c|c|c|c|c|c|c|c|c|}
\hline \multicolumn{3}{|l|}{$20-29$} & \multicolumn{3}{|l|}{$30-39$} & \multicolumn{3}{|c|}{40 and Above } & \multirow{2}{*}{$\begin{array}{l}\text { Chi-square value } \\
6.198\end{array}$} & \multirow{2}{*}{$\frac{\text { p-value }}{0.185}$} \\
\hline $11(13.8)$ & $2(8.0)$ & $5(21.7)$ & 27 (33.7) & $9(36.0)$ & $12(52.2)$ & $42(52.5)$ & $14(56.0)$ & $6(26.0)$ & & \\
\hline $5(9.2)$ & $6(23.0)$ & $7(14.6)$ & $26(48.1)$ & $3((11.5)$ & $19(39.6)$ & $23(42.6)$ & $17(65.0)$ & $22(45.8)$ & 10.749 & $0.030 *$ \\
\hline $9(10.8)$ & $1(12.5)$ & $8(21.6)$ & $23(27.7)$ & $4(50.0)$ & $21(56.8)$ & $51(61.5)$ & $3(37.5)$ & $8(21.6)$ & 16.832 & $0.002 *$ \\
\hline $6(8.7)$ & $1(3.3)$ & $8(30.8)$ & $18(26.1)$ & $16(53.4)$ & $14(53.8)$ & $45(65.2)$ & $13(43.3)$ & $4(15.4)$ & 20.566 & $<0.001^{*}$ \\
\hline $13(10.7)$ & $4(66.8)$ & $1(100.0)$ & 47 (38.9) & $1(16.6)$ & $0(0.0)$ & $61(50.4)$ & $1(16.6)$ & $0(0.0)$ & 20.966 & $<0.001^{*}$ \\
\hline $8(66.7)$ & $7(77.8)$ & $3(2.8)$ & $3(25.0)$ & $1(11.1)$ & $44(41.1)$ & $1(8.3)$ & $1(11.1)$ & $60(56.1)$ & 69.647 & $<0.001^{*}$ \\
\hline
\end{tabular}

the questionnaire. Third; some questionnaire were filled by the family members and/or their caregivers, in other words, their information may be considered secondhand.

\section{CONCLUSION}

It can be found that the patients' perception on the pharmacists' skills and knowledge in handling psychiatric patients is high, but they were not generally satisfied with the pharmacists' professional outlook. Moreover, the patients expect the pharmacists to reach out to them, counsel them on their medication use, and possibly find solutions to their medication needs. Hence, the patients' views on pharmacists' art of counseling can be considered to be generally poor.
For pharmacists to be seen by these group of patients as highly relevant in mental health care, they should be proactive by ensuring special trainings with role plays in the mandatory continuing education for pharmacists. Furthermore, there must be continuum for advanced training in mental health care for all the pharmacists working in psychiatric hospitals. The results of this study may serve as a guide while undergoing the trainings.

\section{ACKNOWLEDGMENT}

My Special and Sincere thanks go to Prof. Mattew Arhewoh of Department of Pharmaceutics, Faculty of Pharmacy, and University of Benin, Nigeria; for his guidance, encouragement and expert advice. 
I must also thank Dr. Obinna Ekwunife, Dr. Sunday Nduka, Dr. Brian Ogbonna, all from Dept. of Clinical Pharmacy and Pharmacy Management, Faculty of Pharmaceutical Sciences, Nnamdi Azikiwe University, Nigeria, for their continued support and encouragements to building my career. I will like to express my gratitude to my dear wife (Mrs. Rita Ofor), my children (Mmesoma and David), my siblings and my Parents (Engr. Peter and Mrs. Adeline Ofor) for their steadfastness and belief in me; and also the volunteers who participated in the study for their valuable contributions. Above all, I thank the almighty God for giving me the grace to get to this point.

\section{AUTHORS' CONTRIBUTIONS}

The author conducted the study, collected the data, and wrote the article.

\section{CONFLICTS OF INTEREST}

The author declares no conflicts of interest.

\section{AUTHORS' FUNDING}

Publication of the article was sponsored by Kenal Pharmaceutical Ltd, Ogidi, Anambra State, Nigeria.

\section{REFERENCES}

1. Saraceno B. The WHO World health report 2001 on mental health. Epidemiol Psichiatr Soc 2002;11:83-7.
2. Jannah C. 40 Million Nigeria Suffering Mental Disorders-Nigeria Government, Daily Post; 2018. Available from: http://www.dailypost. ng $>$ health.

3. Oyewobi A. Youth Account for $85 \%$ of Psychiatric Cases in Nigeria-Group, Premium Times; 2018. Available from: http://www. premiumtimesng.com $>$ news.

4. Charlson F, Ommerem M, Flaxman A, Cornett J, Whiteford H, Saxena S. New WHO prevalence estimates of mental disorders in conflict settings: A systematic review and meta-analysis. Lancet 2019;394:240-8

5. Bawazir S. Consumer attitudes towards community pharmacy services in Saudi Arabia. Int J Pharm Pract 2004;12:83-9.

6. Gidman W, Ward P, McGregor L. Understanding public trust in services provided by community pharmacists relative to those provided by general practitioners: A qualitative study. BMJ Open 2012;2:e00939.

7. Hajj M, Salem S, Mansoor H. Public's attitudes towards community pharmacy in Qatar: A pilot study. Patient prefer adherence 2001;5:405-22.

8. Khanfar N, Alkhateeb F, Clauson K, Beckey C. Patient attitudes toward community pharmacist attire. J Pharm Pract 2012;26:442-7.

9. Cretton-Scott E, Johnson L, King S. Pharmacist attire and its impact on patient preference. Pharm Pract (Granada) 2011;9:66-71.

10. Liu MY, Jennings JP, Samuelson WM, Sullivan CA, Veltri JC. Asthma patients' satisfaction with the frequency and content of pharmacist counseling. J Am Pharm Assoc (Wash) 1999;39:493-8.

11. Ofor A, Nduka S, Ukwe C. Impact of community pharmacy-based asthma education program on the patients' clinical and humanistic outcomes. Sci Res J 2020;8:11-28.

12. Mitchell P. Age-related differences in doctor-patient interaction and patient satisfaction. Curr Gerontol Geriatr Res 2011;2011:137492. 